\title{
Subcutaneous Cavernous Hemangioma in the Nasal Dorsum: Report of Case Treated with Endoscopic Rhinoplasty
}

\author{
Jan Alessandro Socher ${ }^{1}$ Maurício F. de Sá Marchi² \\ ${ }^{1}$ Department of Otorhinolaryngology, Regional University of \\ Blumenau Foundation (Fundação Universidade Regional de \\ Bumenau-FURB), Blumenau/SC, Brazil \\ 2 Department of Medicine, Regional University of Blumenau \\ Foundation (Fundação Universidade Regional de Bumenau-FURB), \\ Blumenau/SC, Brazil
}

\author{
Jeniffer C. Kozechen Rickli²
}

\author{
Address for correspondence Prof. Dr. Jan Alessandro Socher, PhD, \\ Alameda Duque de Caxias, 145 sala 306, Bairro Centro, CEP 89015-010, \\ Blumenau/SC, Brazil (e-mail: otorhinus_blumenau@yahoo.com.br).
}

\begin{abstract}
Keywords

- hemangioma

- cavernous

- rhinoplasty

- natural orifice endoscopic surgery

Introduction Hemangiomas are vascular malformations, with slow blood flow, that can occur in any part on the body. They are more common in women and, predominantly, are isolated lesions. The malformation does not spontaneously regress. Subcutaneous hemangioma is a rare variant with an aggressive growth pattern that sometimes recurs after excision. Objective Case report of a subcutaneous cavernous hemangioma in the nasal dorsum treated with endoscopic rhinoplasty.

Resumed Report A 27-year-old woman had a fibroelastic tumor mass in the midline of the nasal dorsum, which was pulsatile; she had obstruction and nasal congestion with associated rhinorrhea, with evolution and worsening over the previous 2 years. Computed tomography showed a tumor demarcated in the nasal dorsum without evidence of intracranial communication. Endoscopic rhinoplasty with septoplasty and associated paranasal sinus sinusectomy was performed without arteriography embolization, sclerotherapy, or laser. Pathologic diagnosis showed cavernous hemangioma. Postoperative follow-up shows no recurrence at 3 years.

Discussion This case presented with atypical features, thus making the diagnosis a challenge. Imaging studies were required to confirm the vascular nature of the tumor. Excisional biopsy is the procedure of choice for pathologic examination. Subcutaneous hemangiomas never involute and always need treatment. The surgical approach is exceptional because there was no preoperative diagnosis. In addition, the closed technique provided best aesthetic results in this case.

Conclusion Endoscopic rhinoplasty is suitable for nasal dorsum tumor resection and has superior aesthetic result to open techniques.
\end{abstract}

\section{Introduction}

Subcutaneous hemangioma is a rare variant of slow-flow venous malformations. ${ }^{1}$ It occurs in both adults and children and is more prevalent in females. ${ }^{2}$ It shows an aggressive growth pattern, can occur in any part of the body, and sometimes recurs after excision. ${ }^{1,3,4}$ The clinical features include local whitening of the skin, followed often by the formation of thin telangiectasias progressing to a cherry-red stain. They are usually papular lesions of a variable thickness that may encompass both superficial and deep layers of the dermis, including subcutaneous regions, giving the lesion a received

September 30, 2012

accepted

April 15, 2013
DOI http://dx.doi.org/

10.1055/s-0033-1351675. ISSN $1809-9777$.
Copyright $\odot 2014$ by Thieme Publicações License terms Ltda, Rio de Janeiro, Brazil 
bluish aspect. ${ }^{5,6}$ Nasal hemangiomas account for $15.8 \%$ of all the facial hemangiomas. The complications caused by the tumor include uni- or bilateral nasal obstruction, changes in valve and nasal septum, ulcerations, amblyopia, heart and respiratory failure, feeding difficulties, bleeding, and infections, along other psychosocial factors. ${ }^{7,8}$ The differential diagnosis includes lymphatic malformations, pyogenic granuloma, gliomas, and other benign and malignant tumors. ${ }^{9}$

\section{Objective}

We report a case of localized subcutaneous cavernous hemangioma of the nasal dorsum treated through endoscopic rhinoplasty.

\section{Case Report}

A 27-year-old woman was sent to an otolaryngology service in Blumenau/SC for evaluation of a tumor mass in the midline of the nasal dorsum, with a history of worsening over the past 2 years. The patient complained of nasal congestion associated with obstruction and rhinorrhea. Physical examination revealed a tumor in the midline of the nasal dorsum, with a fibroelastic, pulsatile, and motionless aspect, presenting hyperemia of the skin color and no sign of ulceration (-Fig. 1). The videoendoscopic exam showed a deviated nasal septum, hypertrophy of the inferior turbinates, and bilateral hyaline rhinorrhea in the middle nasal meatus. The computed tomography (CT) scan and nuclear magnetic resonance (NMR) of the paranasal sinuses and nasal cavity, with and without contrast, in the axial, coronal, and sagittal planes revealed a tumor restricted to the nasal dorsum, without evidence of intracranial communicationto the nasal cavities, with little contrast impregnation (-Figs. 2 and 3). Endoscopic rhinoplasty was planned for resection of the tumor, along with septoplasty surgery and sinusotomy of the paranasal sinuses. The patient was treated in the hospital under general anesthesia and orotracheal intubation. Closed rhinoplasty was performed, with an intercartilaginous incision to approach the nasal dorsum, using an endoscopic technique for complete resection of the subcutaneous tumor with a margin of safety and
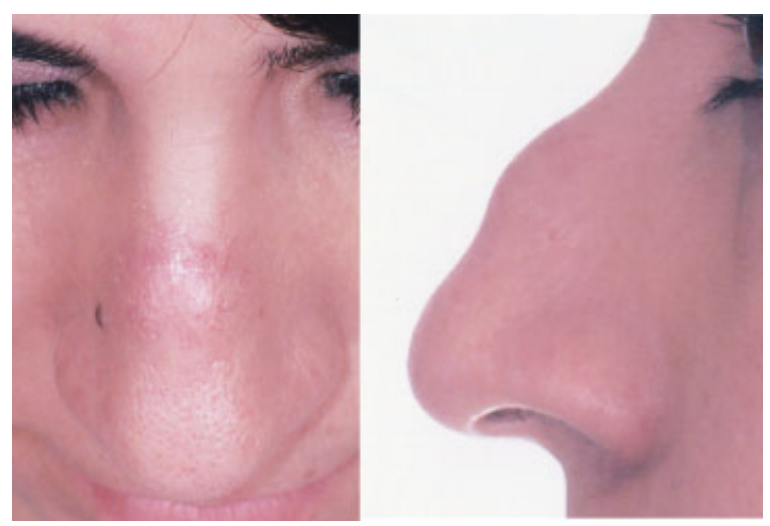

Fig. 1 Front and profile photographs showing the detail of the tumor mass in the midline of the nasal dorsum, along with fibroelastic, pulsatile, and motionless aspect, presenting hyperemia of the skin.

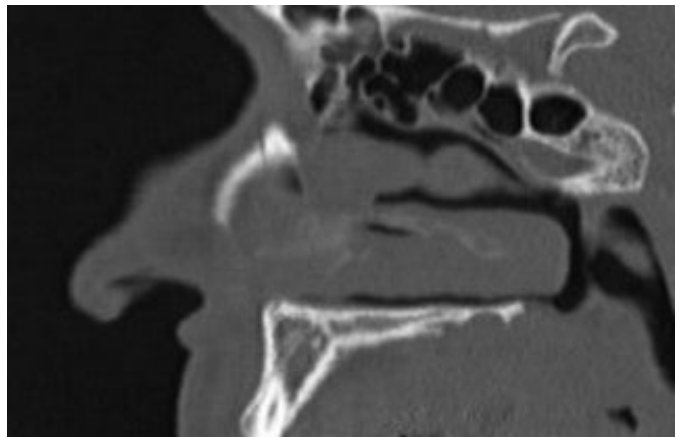

Fig. 2 Computed tomography scan in sagittal plane identifying discrete area of contrast enhancement of soft tissue in the nasal dorsum.

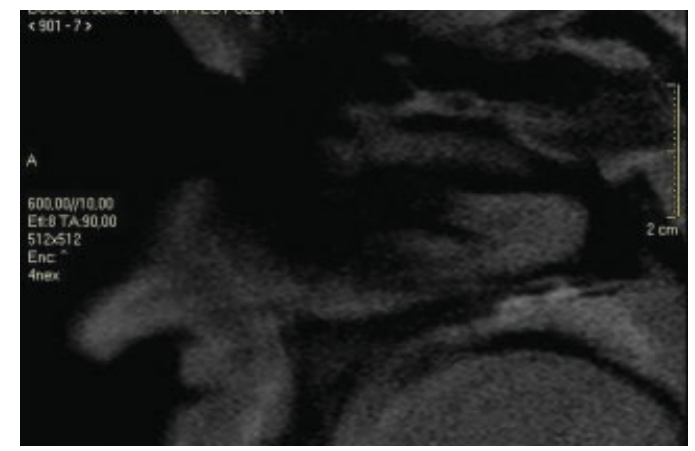

Fig. 3 Nuclear magnetic resonance in sagittal plane identifying discrete area of contrast enhancement in the nasal dorsum.

preservation of the cutaneous tissue of the nasal dorsum (-Fig. 4). Arteriography with superselective embolization, sclerotherapy, and laser were not used beforehand or even during the surgical procedure. The pathologic diagnosis was confirmed postoperatively as cavernous hemangioma of the nasal dorsum (-Fig. 5). The patient was followed weekly for the first postoperative month, biweekly during the second postoperative month, then monthly until the sixth month.

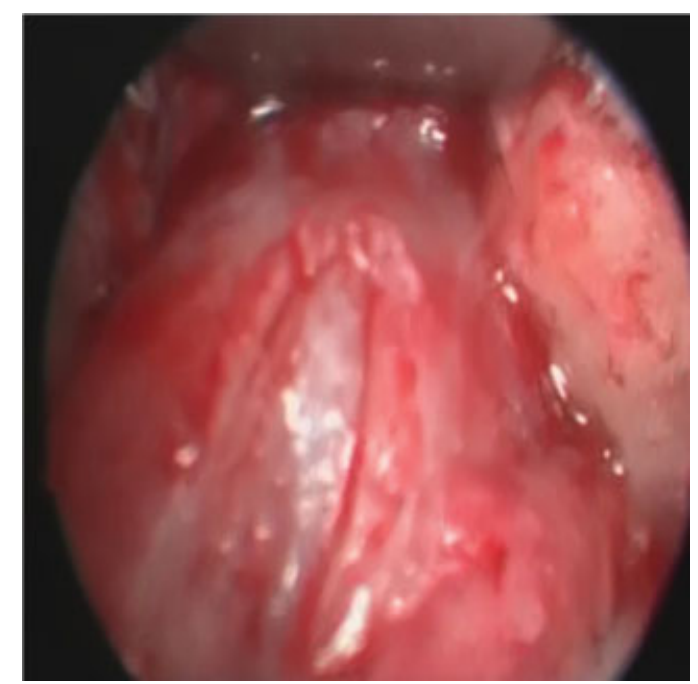

Fig. 4 Intraoperative endoscopic visualization with 30-degree optic demonstrating complete tumor resection of the nasal dorsum. 
While monitoring every 6 months until postoperative year 3, there were no detectable signs of tumor recurrence and the patient was satisfied with cosmetic and functional results.

\section{Discussion}

Cavernous hemangiomas are tumors formed by vascular ectasia. They can be located deeper in the skin and mucous membranes, but also can involve deeper structures such as subcutaneous tissue, muscle, bone. Hemangiomas may be localized or diffuse. In this case, we identified a case of subcutaneous cavernous hemangioma with atypical clinical features on the nasal dorsum; differential diagnosis should be done with all midline nasal tumors, such as nasal gliomas, meningocele or meningoencephaloceles, dermoid cysts, teratomas, sebaceous cysts, papillomas, lipomas, fibromas, and others. ${ }^{10,11}$

Although the diagnosis may be exclusively clinical on the superficial lesions, cavernous hemangiomas can still be identified through the patient's history and by the lesion characteristics on clinical examination. Imaging tests such as ultrasound, CT, or magnetic resonance imaging (MRI) are needed to confirm the vascular nature and identify the venous, arterial, or lymphatic components and involvement of deeper structures. Regardless, in atypical cases the diagnosis can be difficult. ${ }^{12}$

Hemangiomas are congenital malformations that are present since birth, when they are still incipient. They evolve with progression proportional to the child's growth or with an abrupt increase occurring from hormonal changes or local pressure or as a result of injuries, which may explain the behavior in this case with such late growth. ${ }^{4}$

Radiologic studies are important in the investigation of lesions of the nasal dorsum midline. Pensler cites that CT examination is essential to detect defects at the foramen cecum and helps rule out intracranial communication in some cases. ${ }^{13}$ According to Lusk et al, MRI may be more useful to assess soft tissue and intracranial communication;

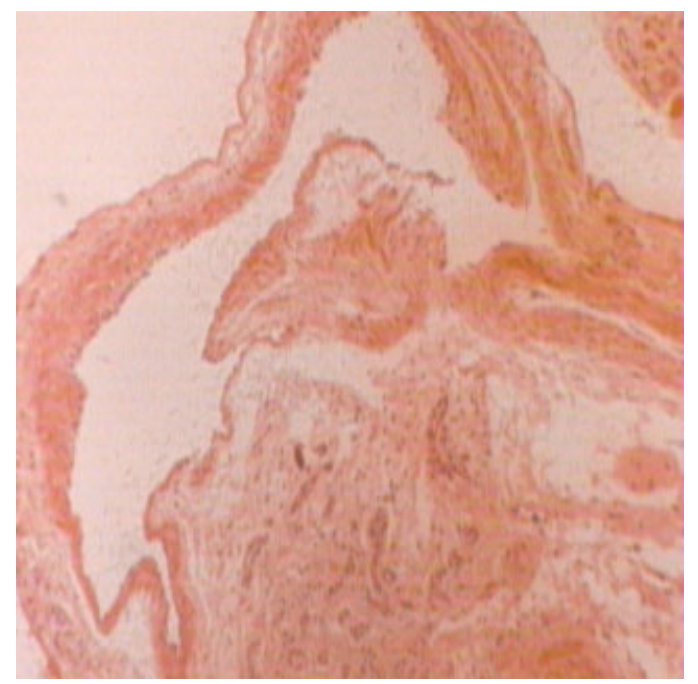

Fig. 5 Cavernous hemangioma: photomicrograph showing blood vessels juxtaposed with ample light and fibrous wall lined by a single layer of endothelium. (Hematoxylin staining, $100 \times$.) furthermore, no radiation exposure is reported. ${ }^{14}$ To Barkovich et al, MRI should be the test of choice for the "screening" of initial patient with midline nasal mass. In this case, neither CT nor MRI elucidated connection with the mass of the CNS. ${ }^{15}$ Negative results on imaging studies, even with contrast, do not exclude the intracranial communication.

The diagnosis and confirmation of nasal dorsum midline tumors were obtained through pathologic examination; excisional biopsy is the gold standard procedure and an incisional biopsy is never indicated, because it may lead to meningitis and cerebrospinal fluid leak due to tumor communication and common intracranial bleeding of hemangiomas. ${ }^{10,11}$ In this case, we obtained the diagnosis of cavernous hemangioma postoperatively, after the tumor resection.

Cavernous hemangiomas never involute and should always be treated. Treatment modalities commonly employed in these cases are sclerotherapy and use of laser. Embolization by superselective arteriography is restricted to cases with an arterial component or arteriovenous fistula. The feasibility of removing a cavernous hemangioma depends of the characteristics and where the lesion is located and must be indicated only when it would not cause functional or aesthetic problems. The surgical approach was considered exceptional in this circumstance because there was no preoperative diagnosis and the case was treated as a midline tumor of the nasal dorsum. Yokoyama et al advocate for endoscopic resection of tumor of the nasal midline when it has no intracranial extension, because the external accesses are associated with aesthetic problems postoperatively. ${ }^{11}$ Closed technique by endoscopic resection was chosen to obtain better aesthetic result and provide greater safety of tumor resection and margins, without need of an external incision and/or skin tissue resection of the nasal dorsum.

\section{Conclusion}

Endoscopic rhinoplasty has shown to be an appropriate technique for the resection of tumors of the nasal dorsum, including cavernous hemangioma, presenting no signs of recurrence and with aesthetic results superior to open techniques.

\section{References}

1 Enjolras O. Malformações vasculares. In: Bolognia JL, Jorizzo JL, Rapini RP, eds. 2nd ed. Rio de Janeiro, Brazil: Elsevier; 2011:1581-1595

2 Gorlin RJ, Kantaputra P, Aughton DJ, Mulliken JB. Marked female predilection in some syndromes associated with facial hemangiomas. Am J Med Genet 1994;52:130-135

3 Casanova D, Norat F, Bardot J, Magalon G. [Cutaneous hemangioma: clinical aspects]. Ann Chir Plast Esthet 2006;51:287-292

4 Boon LM, Mulliken JB, Enjolras O, Vikkula M. Glomuvenous malformation (glomangioma) and venous malformation: distinct clinicopathologic and genetic entities. Arch Dermatol 2004;140:971-976

5 Hochman M, Adams DM, Reeves TD. Current knowledge and management of vascular anomalies: I. Hemangiomas. Arch Facial Plast Surg 2011;13:145-151

6 Antaya RJ, Ortonne JP, Wells MJ, Perry V, Gelfand JM, James WD. Infantile hemangioma. In: Emedicine. Updated May 20, 2013. Available at: http://emedicine.medscape.com/article/1083849-overview. Accessed August 20, 2013 


\section{Subcutaneous Cavernous Hemangioma in the Nasal Dorsum Socher et al.}

7 Simic R, Vlahovic A, Subarevic V. Treatment of nasal hemangiomas. Int J Pediatr Otorhinolaryngol 2009;73:1402-1406

8 Waner M, Kastenbaum J, Scherer K. Hemangiomas of the nose: surgical management using a modified subunit approach. Arch Facial Plast Surg 2008;10:329-334

9 Cohen M, Caputy G, Ben-Amitai D, et al. Plastic surgery for hemangioma workup. In: Emedicine. Updated August 7, 2013. Available at: http://emedicine.medscape.com/article/1296001-workup. Accessed August 20, 2013

10 Harley EH. Pediatric congenital nasal masses. Ear Nose Throat J $1991 ; 70: 28-32$
11 Yokoyama M, Inouye N, Mizuno F. Endoscopic management of nasal glioma in infancy. Int J Pediatr Otorhinolaryngol 1999;51:51-54

12 Reilly JR, Koopman CF, Cotton R. Nasal mass in a pediatric patient. Head Neck 1992;14:415-418

13 Pensler JM, Ivescu AS, Ciletti SJ, Yokoo KM, Byrd SE. Craniofacial gliomas. Plast Reconstr Surg 1996;98:27-30

14 Lusk RP, Lee PC. Magnetic resonance imaging of congenital midline nasal masses. Otolaryngol Head Neck Surg 1986;95(3 Pt 1):303-306

15 Barkovich AJ, Vandermarck P, Edwards MS, Cogen PH. Congenital nasal masses: CT and MR imaging features in 16 cases. AJNR Am J Neuroradiol 1991;12:105-116 